\title{
openheart A systematic review of ICD complications in randomised controlled trials versus registries: is our 'real-world' data an underestimation?
}

\author{
Vivienne A Ezzat, Victor Lee, Syed Ahsan, Anthony W Chow, Oliver Segal, \\ Edward Rowland, Martin D Lowe, Pier D Lambiase
}

To cite: Ezzat VA, Lee V, Ahsan S, et al. A systematic review of ICD complications in randomised controlled trials versus registries: is our 'real-world' data an underestimation?. Open Heart 2015;2:e000198.

doi:10.1136/openhrt-2014000198

Received 19 September 2014 Revised 15 December 2014 Accepted 12 January 2015

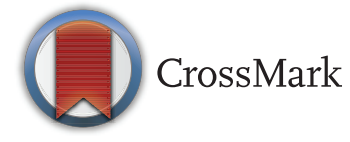

The Heart Hospital, London, UK

Correspondence to Dr Pier D Lambiase; pier. lambiase@uclh.nhs.uk

\section{ABSTRACT}

Implantable cardioverter defibrillator (ICD) implantation carries a significant risk of complications, however published estimates appear inconsistent. We aimed to present a contemporary systematic review using metaanalysis methods of ICD complications in randomised controlled trials (RCTs) and compare it to recent data from the largest international ICD registry, the US National Cardiovascular Data Registry (NCDR).

PubMed was searched for any RCTs involving ICD implantation published 1999-2013; 18 were identified for analysis including 6433 patients, mean follow-up 3 months -5.6 years. Exclusion criteria were studies of children, hypertrophic cardiomyopathy, congenital heart disease, resynchronisation therapy and generator changes.

Total pooled complication rate from the RCTs (excluding inappropriate shocks) was $9.1 \%$, including displacement $3.1 \%$, pneumothorax $1.1 \%$ and haematoma $1.2 \%$. Infection rate was $1.5 \%$. There were no predictors of complications but longer follow-up showed a trend to higher complication rates ( $p=0.07)$. In contrast, data from the NCDR ICD, reporting on 356515 implants (2006-2010) showed a statistically significant threefold lower total major complication rate of $3.08 \%$ with lead displacement $1.02 \%$, haematoma $0.86 \%$ and pneumothorax $0.44 \%$.

The overall ICD complication rate in our meta-analysis is $9.1 \%$ over 16 months. The ICD complication reported in the NCDR ICD registry is significantly lower despite a similar population. This may reflect under-reporting of complications in registries. Reporting of ICD complications in RCTs and registries is very variable and there is a need to standardise classification of complications internationally.

\section{INTRODUCTION}

The implantable cardioverter defibrillator (ICD) is a now established treatment for many individuals considered to be at an increased risk of sudden cardiac death. ${ }^{1}$ The survival benefit appears to be comparable between clinical trial patients and those observed in real world practice. ${ }^{2}$ However, ICD implantation inevitably carries a risk of complications.
Implanters rely on locally available data as well as that reported in the international literature to inform patients of the risks involved. This information may be particularly important when considering implantation for a borderline indication. When benchmarking their practice, institutions may base their targets on figures derived from published data, utilising complementary resources such as registries and randomised clinical trials (RCTs). However, there is a paucity of consistent data on the complication rates of ICD implantation in the modern era. The most recent systematic review of the evidence from $\mathrm{RCTs}^{3}$ was a mixed study of both ICD and cardiac resynchronisation therapy (CRT) devices with series dating back to 1996, including a number of devices implanted by thoracotomy and the incidence of infection was not reported. Although registry data are available, it is not clear how these compare to that compiled from RCTs. Despite this, registry data have recently been utilised to develop a risk model for adverse events during ICD implantation. ${ }^{4}$

Therefore, this study aimed to compare the complication rates reported in RCTs with the so-called 'real-world' experience observed in registries and to examine the quality of complication reporting in the literature in order to assess whether registry data really can be utilised to reflect current real-world experience. The study assessed the risk of complications from contemporary ICD implantation by a pooling of results from RCTs using meta-analysis methods and compared this data to the largest ICD registry to date. ${ }^{5}$

\section{METHODS}

\section{Literature review, inclusion and exclusion} criteria

PubMed was searched on 31 July 2013 for English language RCTs in humans, with abstracts available, using the following criteria: 
(implantable cardioverter defibrillator OR ICD) AND (complications OR adverse event) NOT ICD-9 NOT ICD-10. This identified 187 articles which were screened and of these, 17 met the criteria for inclusion, which were any RCT reporting explicit data on transvenous, nonthoracotomy ICD complications (except inappropriate ICD intervention) regardless of whether or not the study was primarily of ICDs. In the case of serial publications, only the most recent or most appropriate study was included in the analysis. Exclusion criteria were studies specifically of hypertrophic cardiomyopathy (HCM), children, congenital heart disease, resynchronisation therapy and generator changes. Complications of ICD implantation occurring in patients with HCM have recently been comprehensively presented in a review by Schinkel $e t a t^{6}$ The IRIS study ${ }^{7}$ (which was not returned in the original search due to use of the MESH term 'adverse effects' rather than 'adverse events') was also subsequently included in the analysis, thus bringing the total number of RCTs to 18.

\section{Data extraction}

Selected RCTs were reviewed and relevant patient characteristics, potential risk factors for complications and follow-up duration were recorded. No time restriction for complications was used. Even after exclusion of studies without explicit complication data, the studies varied greatly in the manner and depth in which complications were reported and not all described a detailed breakdown. The outcome data available therefore varied according to the criteria used in each particular RCT. An inclusive list of the different complication categories used by the studies is as follows: total complications, 30-day mortality, pneumothorax, haemothorax, haematoma, bleeding, dissection, perforation, tamponade, need for transfusion, thrombosis, displacement, displacement requiring repositioning, other displacement, lead failure or dislodgement, need for lead revision/replacement, need for additional lead, lead fracture, insulation failure, lead under sensing, $\mathrm{T}$ wave over sense, generator failure, generator migration/erosion, generator revision, infection, erosion and Twiddler's syndrome.

\section{Statistical analysis}

Statistical analysis was performed using Microsoft Excel 2010 (Microsoft Corporation, Redmond, Washington, USA) and COMPREHENSIVE META-ANALYSIS software V.2, Biostat, Englewood, USA. Complication event rates were pooled together using inverse variance weighting. Heterogeneity among the studies was evaluated using the $I^{2}$ index. Publication bias was assessed by Begg's adjusted rank correlation test and Egger's regression asymmetry test. Continuous variables were reported as mean. Categorical variables were summarised as percentages. From the pooled data, a fixed effects model was used to calculate summary estimates of patient characteristics and potential risk factors for complications. Meta regression analysis was used to investigate if any variable was associated with specific study outcomes. Poisson regression was used to comparing data from RCTs to that from the registry.

\section{RESULTS \\ Included studies}

The literature search yielded 187 articles. The abstracts or full text of these were reviewed and a total of 17 included in the systematic review with one further study added later. ${ }^{7}$ Baseline characteristics are shown in table 1. A total of 6796 patients were included in the analysis. All were non-thoracotomy systems. Year of publication ranged from 2001 to 2011. Average mean follow-up period was 17.9 months.

\section{Complications}

A total of 532 patients (pooled event rate $9.1 \%$ ) had an ICD-related complication. All complications were considered to be major in that they required intervention or further hospitalisation. The authors chose to classify complications where possible into the following categories:

1. Access-related: This refers to any complication that was vessel-related or occurred while gaining access to the vasculature or the device pocket. This includes pneumothorax, haemothorax, haematoma (including need for transfusion) and thrombosis.

2. Lead-related: Lead-related refers to any complication caused by placement of the lead or subsequently related directly to the lead, for example, dissection or perforation (to include tamponade), displacement, fracture, undersensing or oversensing, insulation defects and the need for any lead revision regardless of cause.

3. Generator-related: This includes generator failure and any need for generator revision, for example, migration or erosion but excluding infection which was classified separately.

4. Infection: This included (where specified) infection requiring intervention, including the use of antibiotic therapy or device extraction.

Complication rates of the aforementioned categories are shown in table 2 including the most uniformly reported individual complications-pneumothorax, haematoma and lead displacement.

On meta regression the only variable showing a relationship with complication rate was length of follow-up which was of borderline statistical significance $(p=0.07)$. A 6-month increase in follow-up time was associated with a $15 \%$ increase in complication rate $(95 \% \mathrm{CI}-2 \%$ to $34 \%$ increase). There was no evidence that year of publication, age, gender, presence or absence of diabetes or ischaemic heart disease or ejection fraction $(\mathrm{EF})$ were associated with rates of complications.

Mortality: In-hospital and 30 day mortality were not consistently reported in the trials, although some specified that there were no 'implant-related deaths'. Given the high-risk nature of many patients receiving ICDs, it may be difficult to ascertain the extent to which an ICD implant per se has contributed to any subsequent early death. Of 
Table 1 Baseline characteristics of the included studies

\begin{tabular}{|c|c|c|c|c|c|c|c|c|c|c|}
\hline & & Trial & Year & $\mathbf{N}$ & $\begin{array}{l}\text { Mean } \\
\text { Follow-up } \\
\text { (months) }\end{array}$ & $\begin{array}{l}\text { Mean } \\
\text { age } \\
\text { (years) }\end{array}$ & $\begin{array}{l}\text { Per cent } \\
\text { male }\end{array}$ & $\begin{array}{l}\text { Mean } \\
\text { EF (\%) }\end{array}$ & $\begin{array}{l}\text { Per cent } \\
\text { IHD }\end{array}$ & $\begin{array}{l}\text { Per cent } \\
\text { DM }\end{array}$ \\
\hline 1 & Calkins et $a P^{3}$ & $\begin{array}{l}\text { SCV vs cephalic } \\
\text { approach }\end{array}$ & 2001 & 71 & 18 & 65 & 61 & 42 & NA & NA \\
\hline 2 & Deisenhofer et af4 & $\begin{array}{l}\text { Dual vs single } \\
\text { chamber }\end{array}$ & 2001 & 92 & 8 & 61 & 90 & NA & 67 & NA \\
\hline 3 & Kron et $a \beta^{\beta}$ & AVID & 2001 & 539 & 27 & 65 & 79 & 32 & 81 & 26 \\
\hline 4 & Bänsch et $a$ F $^{25}$ & CAT & 2002 & 50 & 66 & 52 & 86 & 24 & 0 & NA \\
\hline 5 & Moss et $a^{26}$ & MADIT & 2002 & 742 & 20 & 64 & 84 & 23 & 100 & 33 \\
\hline 6 & Vollman et $a^{{ }^{7}}$ & 6944 vs 6942 & 2003 & 542 & 11 & 65 & 83 & 34 & 72 & NA \\
\hline 7 & Bänsch et $a^{28}$ & $1+1$ & 2004 & 102 & 12 & NA & NA & 38 & 82 & NA \\
\hline 8 & Bokhari et a ${ }^{29}$ & CIDS subset & 2004 & 60 & 67 & 64 & 83 & 34 & 80 & 12 \\
\hline 9 & Hohnloser et $a^{\beta 0}$ & DINAMIT & 2004 & 310 & 30 & 62 & 81 & 28 & 100 & 31 \\
\hline 10 & Kadish et $a l^{11}$ & DEFINITE & 2004 & 229 & 29 & 58 & 72 & 21 & 0 & 23 \\
\hline 11 & Bänsch et $a{ }^{\beta 1}$ & Quick-ICD & 2007 & 190 & 12 & 63 & 86 & 41 & 64 & NA \\
\hline 12 & Reddy et $a^{\beta 2}$ & SMASH-VT & 2007 & 128 & 22 & 67 & 87 & 32 & 100 & 44 \\
\hline 13 & Almendral et $a l^{10}$ & DATAS & 2008 & 334 & 15 & 64 & 84 & 36 & 85 & 24 \\
\hline 14 & Russo et $a \beta^{33}$ & INTRINSIC RV & 2009 & 1530 & 11 & 65 & 81 & NA & 58 & 27 \\
\hline 15 & Steinbeck et al & IRIS & 2009 & 415 & 37 & 63 & 83 & 35 & 77 & 37 \\
\hline 16 & Kuck et $a \beta^{34}$ & VTACH & 2010 & 107 & 23 & 66 & 93 & 34 & 100 & NA \\
\hline 17 & Varma et $a 1^{35}$ & TRUST & 2010 & 1339 & 11 & 64 & 72 & 29 & 67 & NA \\
\hline \multirow[t]{2}{*}{18} & Cheng et $a l^{\beta 6}$ & Warfarin & 2011 & 16 & 1 & 71 & 79 & 37 & 49 & 23 \\
\hline & Summary estimate & & & 6796 & 17.9 & 64 & 80 & 30.5 & 74.0 & 29.1 \\
\hline
\end{tabular}

the six 30-day deaths occurring in the AVID study, ${ }^{8}$ two were potentially related to device implantation.

\section{Registry data}

The largest registry population of ICD patients is the US National Cardiovascular Data Registry (NCDR) ICD registry. A report specifically looking at the relationship between physician procedure volume and ICD complication published in 2012, ${ }^{5}$ included 356515 initial ICD implantations performed between 2006 and 2010. This study was chosen as the most contemporaneous registry to our RCT meta-analysis population and was comparable also in age, gender and left ventricular (LV) function (73\% male, mean age 67.3 years and mean EF 28\%). For this registry population, the total in-hospital complication rate (defined as cardiac arrest, cardiac perforation, valve injury, coronary venous dissection, haemothorax, pneumothorax, deep vein thrombosis, transient ischaemic attack, stroke, myocardial infarction, pericardial tamponade, arteriovenous fistula, drug reaction, conduction block, haematoma, lead dislodgement, peripheral embolus, superficial phlebitis, peripheral nerve injury and device-related infection) was $3.08 \%$; lead displacement was $1.02 \%$, haematoma $0.86 \%$ and pneumothorax $0.44 \%$. Infection rate was not separately reported. A comparison of the complication rates reported in our review and from the registry data is shown in figure 1 . Complication rates reported in the RCTs were significantly higher than those reported in the registry.

A more recent publication covering the periods quarter 2 to quarter 4 of 2010 and all 4 quarters of
2011, including 263284 procedures performed in 259395 patients (including children), reported a total adverse event rate of $2.16 \%$, that is, lower than that reported in the previous 5 years (as might be expected with increased experience); specifying haematoma requiring treatment at $0.34 \%$, infection $1.49 \%$, perprocedural dislodgement $2.84 \%$, perforation $0.16 \%$ and pericardial tamponade $0.12 \% .{ }^{9}$

\section{Infection}

Infection occurred in $1.5 \%$ of RCTs cases included in this review. All but three of the 10 studies reporting infection rates defined infection as requiring removal of the device, although chronology was not specified. The AVID study defined device infection as requiring hospitalisation or prolongation of hospitalisation (if already hospitalised) with administration of intravenous antibiotics with or without explantation. ${ }^{8}$ The DATAS study did not specify whether or not intervention was required but reported only 'pocket infections', ${ }^{10}$ while the DEFINITE study also did not specify if intervention were required but reported only one 'infection'. ${ }^{11}$ Incidence of infection was not described in the NCDR ICD registry publication from 2012, nor in the most recent previous meta-analysis, ${ }^{3}$ however it was almost identical in the most recent NCDR ICD registry data $(1.49 \%){ }^{9}$

\section{DISCUSSION}

This systematic review of ICD implantation in almost 6800 patients with ischaemic heart disease and dilated 
Table 2 Complications

\begin{tabular}{|c|c|c|c|c|c|c|c|c|c|}
\hline & \multirow[b]{2}{*}{$\begin{array}{l}\text { Patients, } \\
\text { n }\end{array}$} & \multirow[b]{2}{*}{$\begin{array}{l}\text { All events, } \\
\text { n (\%) }\end{array}$} & \multicolumn{3}{|c|}{ Access-related, n (\%) } & \multicolumn{2}{|c|}{ Lead-related, n (\%) } & \multirow[b]{2}{*}{$\begin{array}{l}\text { Generator-related, } \\
\text { n (\%) }\end{array}$} & \multirow[b]{2}{*}{$\begin{array}{l}\text { Infection } \\
\text { n (\%) }\end{array}$} \\
\hline & & & Total & Pneumothorax & Haematoma & Total & Displacement & & \\
\hline Calkins et $a f^{23}$ & 71 & $2(2.8)$ & $1(1.4)$ & - & $1(1.4)$ & $1(1.4)$ & $1(1.4)$ & - & 0 \\
\hline Deisenhofer et $a R^{4}$ & 92 & $10(10.9)$ & $2(2.2)$ & $1(1.1)$ & $1(1.1)$ & $8(8.7)$ & - & - & 0 \\
\hline Kron et $a \beta^{\beta}$ & 539 & $68(12.6)$ & $16(3.0)$ & $6(1.1)$ & $8(1.5)$ & $31(5.8)$ & $11(2.0)$ & $7(1.3)$ & $14(2.6)$ \\
\hline Bänsch et $a{ }^{55}$ & 50 & $14(28)$ & $2(4.0)$ & - & $2(4.0)$ & $10(20.0)$ & $9(18)$ & - & $2(4.0)$ \\
\hline Moss et $a^{26}$ & 742 & $18(2.4)$ & - & - & - & $13(1.8)$ & - & - & $5(0.7)$ \\
\hline Vollman et $a^{p^{7}}$ & 542 & $64(11.8)$ & - & - & - & 45 (8.3) & $8(1.5)$ & - & - \\
\hline Bänsch et $a f^{8}$ & 102 & $20(19.6)$ & - & - & - & $20(19.6)$ & $9(8.8)$ & - & - \\
\hline Bokhari et a ${ }^{29}$ & 60 & $21(35)$ & - & - & - & $18(30)$ & $2(3.3)$ & - & $3(5.0)$ \\
\hline Hohnloser et a ${ }^{\beta 0}$ & 310 & $25(8.1)$ & - & - & - & 7 (2.3) & - & - & - \\
\hline Kadish et $a l^{11}$ & 229 & $13(5.7)$ & $5(2.2)$ & $1(0.4)$ & - & - & - & - & $1(0.4)$ \\
\hline Bänsch et $a l^{\beta 1}$ & 190 & $3(1.6)$ & $1(0.5)$ & - & $1(0.5)$ & $2(1.1)$ & $1(0.5)$ & - & - \\
\hline Reddy et $\left.a\right|^{\beta 2}$ & 128 & 0 & - & - & - & - & - & - & 0 \\
\hline Almendral et $a l^{10}$ & 334 & $30(9.0)$ & $11(3.3)$ & $4(1.2)$ & $4(1.2)$ & $15(4.5)$ & $13(3.9)$ & - & $4(1.2)$ \\
\hline Russo et $\left.a\right|^{33}$ & 1530 & $71(4.6)$ & $15(1.0)$ & - & $15(1.0)$ & $33(2.2)$ & $23(1.5)$ & $38(2.5)$ & - \\
\hline Steinbeck et $a l^{7}$ & 415 & 76 (18.3) & - & - & - & - & - & - & - \\
\hline Kuck et $a 1^{\beta 4}$ & 107 & 15 (14.0) & - & - & - & $6(5.6)$ & $4(3.7)$ & $7(6.5)$ & $1(0.9)$ \\
\hline Varma et $a \beta^{35}$ & 1339 & $81(6.0)$ & - & - & - & - & - & - & - \\
\hline Cheng et $a^{\beta 6}$ & 16 & $1(6.3)$ & - & - & - & - & - & - & - \\
\hline $\begin{array}{l}\text { Event rate, \% } \\
(95 \% \mathrm{Cl})\end{array}$ & & $\begin{array}{l}9.1 \\
(6.4 \text { to } \\
12.6)\end{array}$ & $\begin{array}{l}2.1 \\
(1.3 \text { to } \\
3.3)\end{array}$ & $\begin{array}{l}1.1 \\
(0.6 \text { to } 1.8)\end{array}$ & $\begin{array}{l}1.2 \\
(0.9 \text { to } 1.7)\end{array}$ & $\begin{array}{l}5.8 \\
\text { (3.3 to } \\
9.8)\end{array}$ & $\begin{array}{l}3.1 \\
(1.7 \text { to } 5.8)\end{array}$ & $\begin{array}{l}2.7 \\
(1.3 \text { to } 5.7)\end{array}$ & $\begin{array}{l}1.5 \\
(0.8 \text { to } \\
2.6)\end{array}$ \\
\hline
\end{tabular}




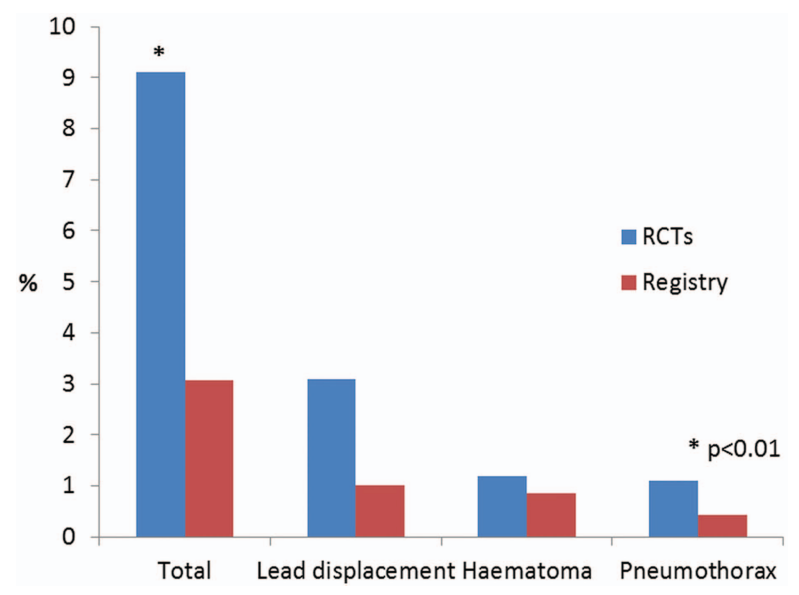

Figure 1 Complication rates in randomised controlled trials (RCTs) compared to registry.

cardiomyopathy enrolled in RCTs, found an overall complication rate of $9.1 \%$, the majority of which arose from early complications of access issues or lead displacement $(5.2 \%)$. This is almost threefold higher than that reported in the NCDR registry publication and importantly may also be more than that often quoted by physicians to patients when considering ICD implantation. Similarly, individual complications of lead displacement, haematoma and pneumothorax were also all higher than those reported by the registry. The only complication rate reported which was comparable between the RCT and registry population in the more recent publication, was infection at $1.5 \%$. A higher event rate in RCTs would not necessarily be expected since many trials may exclude the most high-risk patients and theoretically might therefore represent a less frail population than that of a registry. In addition, patients enrolled in RCTs may potentially be treated by the more experienced operators of a centre while procedures in registry patients might conceivably be performed by operators with a wider range of experience.

There are a number of possible explanations for these findings. There was a wide variation in complication rates observed in the RCTs with the highest rates mainly reported from 2002-2004, reflecting the experience and developments of the late 1990s. Given the slightly more contemporary nature of the registry data it is possible that the lower complication rate reflects increased operator experience and improved device/lead technology. This seems unlikely to be a complete explanation however, given that a number of the larger RCTs (therefore contributing more significantly statistically to the pooled data) included in our review were published in the late 2000s. The relationship between complication rate and length of follow-up, which on meta-regression was of borderline statistical significance $(p=0.07)$, may however be of particular relevance in this context. The follow-up period reported in this meta-analysis was dictated by the data available from the RCTs and was not specifically restricted to either acute or late-presenting complications. It is obviously important to recognise that in contrast, the NCDR data reports specifically on in-hospital complications only. Nevertheless, the fact that early complications of lead displacement, haematoma and pneumothorax rates (all of which present either in-hospital or at early follow-up) were also all higher than in the RCTs than in the registry, indicates that length of follow-up is unlikely to account for these differences between RCT and registry data.

A further reason is that there is significant underreporting of complications in some registry data. From the NCDR ICD registry data in $2010,{ }^{12}$ the mean complication rate for all new ICD implants (2006-2009) was $3.22 \%$, however the median event rate, which may be a more meaningful representation, was $7 \%$ with the highest decile $13 \%$. Interestingly, the Ontario ICD registry of over 3000 patients recorded an overall complication rate of $8.5 \%$ but made a distinction between major and minor complications, ${ }^{13}$ reporting a major complication rate of $4.1 \%$. Minor complications included subclavian vein thrombosis and pocket haematoma which may be considered contentious, for example, given the possible association between haematoma and infection. ${ }^{14}$ The fact that the only complication rate reported which was comparable between the RCT data and most recent registry population was infection, may reflect a recognition of the need for improved accuracy of the reporting of this particular most feared complication.

In a recently published Danish registry experience, ${ }^{15}$ the total complication rate for any cardiovascular implantable electronic device (CIED) was reported as 9.5\%. This study included all patients on the Danish Pacemaker and ICD Register undergoing a CIED procedure from May 2010 to April 2011. Data on complications were collected, by a physician, through a thorough and meticulous review and audit of the original data. Of 5918 consecutive patients, 562 experienced at least one complication. The authors concluded that CIED complications are more frequent than generally acknowledged.

\section{Measuring outcomes and performance}

With a progressive change in attitudes towards the provision and management of healthcare, physicians must now formally address the issues of quality measurement, public reporting and a demand for greater transparency. Accordingly the ability of sources, such as the NCDR ICD registry to correctly capture outcomes and performance is now an important concern and a need for greater accuracy increasingly recognised. The NCDR is the world's largest clinical database of ICD implantation but is still a relatively young institution; its purpose and intention continue to evolve. Originally conceived in 2005 in response to a Medicare mandate on primary prevention ICD implants, it now fulfils a number of roles including acting as a tool for public reporting and postmarket surveillance. Reporting involves a combination of incentive payments and payment adjustments, and is currently voluntary but will become mandatory by 
2015. Of the participating hospitals, $78 \%$ submit data on all ICD implants, accounting for $\sim 90 \%$ of implant data entered into the registry. Data quality checks and randomly selected audits are performed, nevertheless as with any registry, concerns remain about the validity and accuracy of the data. Improving the data collection process is essential; physicians should take responsibility for the quality of data as it will be used to measure performance and quality of care delivery; at the same time, systems must be designed to minimise the burden of accurate data collection in order that it does not become an insurmountably onerous task.

\section{Definition of complications}

This review of data from both RCTs and registries highlights the poor quality of definitions and highly variable reporting of complications across the specialty. It is clear that there is a need to standardise this practice. Expected complication rates and a discussion of the risks of ICD implantation are notably absent in the device guidelines from both the $\mathrm{US}^{16}{ }^{17}$ and European ${ }^{18}$ Heart Rhythm and Cardiac societies, other than in the context of CRT, ${ }^{19}$ where the emphasis is predominantly on problems associated with the LV lead. The authors propose the development and adoption of a universal classification system for the reporting of complications (for all implantable cardiac devices) allowing meaningful data collection, distribution, comparison and practice-benchmarking.

\section{Study limitations}

There are a number of limitations of this study, mainly inherent to this type of analysis. As has already been discussed, a major factor is the variation in reporting of complications which renders collation of data difficult. In addition there are several possible confounders of particular complications which are not known, for example, the proportion of cephalic versus subclavian vein access in the studies in which pneumothoraces occurred, the use of periprocedural antibiotics with regards to infection rate and the proportion of dual versus single chamber devices. Finally since this review focused on implantation only, it did not include details of arguably one of the most serious ICD adverse events for the patient's well-being, namely inappropriate device therapy or more long-term lead-related complications. Given the multifactorial nature of these complications, we believe that this merits a separate analysis.

\section{CONCLUSION}

It is clearly evident that implantation of an ICD/pacing lead carries a significant risk of immediate complications with $1 / 20$ patients suffering an access related events or early lead displacement. This is a reflection of the limitations of current implantation techniques utilising anatomically or fluoroscopy-guided subclavian puncture (when the cephalic vein is unsuitable) without ultrasound guidance. Furthermore, even in the best hands acute lead stability remains an issue. These factors are compounded by the longevity of leads and possibility of multiple replacements particularly in younger patients. The emergence of subcutaneous ICD and now leadless pacing systems may mean some of these complications can be avoided in those not requiring pacing but ventricular defibrillation therapies only.

This systematic review demonstrates a significant rate of complications following ICD implantation and suggests that the incidence observed in RCTs may be higher than that recorded in registry data. A number of commentators have raised the question of under-reporting and under-recognition of complications from ICD implantation in the past. ${ }^{20-22}$ Until we establish robust definitions and methods of data collection, the opacity and uncertainty about true risks (and therefore relative benefits) of device implantation will remain.

Contributors PDL was responsible for concept generation and final review of the manuscript. VAE performed the literature search, wrote and reviewed the manuscript. VL contributed to the statistical analysis and reviewed the manuscript. All other authors reviewed and edited the manuscript.

Funding This work was funded by the UCLH NIHR BRC.

Competing interests None declared.

Provenance and peer review Not commissioned; externally peer reviewed.

Open Access This is an Open Access article distributed in accordance with the Creative Commons Attribution Non Commercial (CC BY-NC 4.0) license, which permits others to distribute, remix, adapt, build upon this work noncommercially, and license their derivative works on different terms, provided the original work is properly cited and the use is non-commercial. See: http:// creativecommons.org/licenses/by-nc/4.0/

\section{REFERENCES}

1. http://guidance.nice.org.uk/TA95

2. Al-Khatib SM, Hellkamp A, Bardy GH, et al. Survival of patients receiving a primary prevention implantable cardioverter-defibrillator in clinical practice vs clinical trials. JAMA 2013;309:55-62.

3. van Rees JB, de Bie MK, Thijssen J, et al. Implantation-related complications of implantable cardioverter-defibrillators and cardiac resynchronization therapy devices: a systematic review of randomized clinical trials. J Am Coll Cardiol 2011;58:995-1000.

4. Dodson JA, Reynolds MR, Bao H, et al. Developing a risk model for in-hospital adverse events following implantable cardioverterdefibrillator implantation: a report from the NCDR (National Cardiovascular Data Registry). J Am Coll Cardiol 2014;63:788-96.

5. Freeman JV, Wang Y, Curtis JP, et al. Physician procedure volume and complications of cardioverter-defibrillator implantation. Circulation 2012;125:57-64.

6. Schinkel AF, Vriesendorp PA, Sijbrands EJ, et al. Outcome and complications after implantable cardioverter defibrillator therapy in hypertrophic cardiomyopathy: systematic review and meta-analysis. Circ Heart Fail 2012;5:552-9.

7. Steinbeck G, Andresen D, Seidl K, et al. Defibrillator implantation early after myocardial infarction. N Engl J Med 2009;361:1427-36.

8. Kron J, Herre J, Renfroe EG, et al. Lead- and device-related complications in the antiarrhythmics versus implantable defibrillators trial. Am Heart J 2001;141:92-8.

9. Kremers MS, Hammill SC, Berul Cl, et al. The National ICD Registry Report: version 2.1 including leads and pediatrics for years 2010 and 2011. Heart Rhythm 2013;10:e59-65.

10. Almendral J, Arribas F, Wolpert C, et al. Dual-chamber defibrillators reduce clinically significant adverse events compared with single-chamber devices: results from the DATAS (Dual chamber and Atrial Tachyarrhythmias Adverse events Study) trial. Europace 2008;10:528-35.

11. Kadish A, Dyer A, Daubert JP, et al. Prophylactic defibrillator implantation in patients with nonischemic dilated cardiomyopathy. N Engl J Med 2004;350:2151-8. 
12. Hammill SC, Kremers MS, Stevenson LW, et al. Review of the registry's fourth year, incorporating lead data and pediatric ICD procedures, and use as a national performance measure. Heart Rhythm 2010;7:1340-5.

13. Lee DS, Krahn AD, Healey JS, et al. Evaluation of early complications related to De Novo cardioverter defibrillator implantation insights from the Ontario ICD database. J Am Coll Cardiol 2010;55:774-82.

14. Uslan DZ, Gleva MJ, Warren DK, et al. Cardiovascular implantable electronic device replacement infections and prevention: results from the REPLACE Registry. Pacing Clin Electrophysiol 2012;35:81-7.

15. Kirkfeldt RE, Johansen JB, Nohr EA, et al. Complications after cardiac implantable electronic device implantations: an analysis of a complete, nationwide cohort in Denmark. Eur Heart $J$ 2014;35:1186-94.

16. Epstein AE, Dimarco JP, Ellenbogen KA, et al. ACC/AHA/HRS 2008 Guidelines for device-based therapy of cardiac rhythm abnormalities. Heart Rhythm 2008;5:e1-62.

17. Tracy CM, Epstein AE, Darbar D, et al. 2012 ACCF/AHA/HRS Focused Update of the 2008 Guidelines for Device-Based Therapy of Cardiac Rhythm Abnormalities: a report of the American College of Cardiology Foundation/American Heart Association Task Force on Practice Guidelines. Heart Rhythm 2012;9:1737-53.

18. Zipes DP, Camm AJ, Borggrefe M, et al. ACC/AHA/ESC 2006 guidelines for management of patients with ventricular arrhythmias and the prevention of sudden cardiac death: a report of the American College of Cardiology/American Heart Association Task Force and the European Society of Cardiology Committee for Practice Guidelines (Writing Committee to Develop guidelines for management of patients with ventricular arrhythmias and the prevention of sudden cardiac death) developed in collaboration with the European Heart Rhythm Association and the Heart Rhythm Society. Europace 2006;8:746-837.

19. Dickstein K, Vardas PE, Auricchio A, et al. 2010 Focused Update of ESC Guidelines on device therapy in heart failure: an update of the 2008 ESC Guidelines for the diagnosis and treatment of acute and chronic heart failure and the 2007 ESC guidelines for cardiac and resynchronization therapy. Developed with the special contribution of the Heart Failure Association and the European Heart Rhythm Association. Eur Heart J 2010;31:2677-87.

20. Anderson KP. Estimates of implantable cardioverter-defibrillator complications: caveat emptor. Circulation 2009;119:1069-71.

21. Brignole M. Are complications of implantable defibrillators under-estimated and benefits over-estimated? Europace 2009;11:1129-33.

22. Brinker JA. Implantable cardioverter-defibrillator lead failure: how weak is the link? Nat Clin Pract Cardiovasc Med 2008;5:758-9.

23. Calkins H, Ramza BM, Brinker J, et al. Prospective randomized comparison of the safety and effectiveness of placement of endocardial pacemaker and defibrillator leads using the extrathoracic subclavian vein guided by contrast venography versus the cephalic approach. Pacing Clin Electrophysiol 2001;24(4 Pt 1):456-64.

24. Deisenhofer I, Kolb C, Ndrepepa G, et al. Do current dual chamber cardioverter defibrillators have advantages over conventional single chamber cardioverter defibrillators in reducing inappropriate therapies? A randomized, prospective study. J Cardiovasc Electrophysiol 2001;12:134-42.

25. Bänsch D, Antz M, Boczor S, et al. Primary prevention of sudden cardiac death in idiopathic dilated cardiomyopathy: the Cardiomyopathy Trial (CAT). Circulation 2002;105:1453-8.

26. Moss AJ, Zareba W, Hall WJ, et al. Prophylactic implantation of a defibrillator in patients with myocardial infarction and reduced ejection fraction. N Engl J Med 2002;346:877-83.

27. Vollmann D, Ahern T, Gerritse B, et al. Worldwide evaluation of a defibrillation lead with a small geometric electrode surface for high-impedance pacing. Am Heart J 2003;146:1066-70.

28. Bänsch D, Steffgen F, Grönefeld G, et al. The 1+1 trial: a prospective trial of a dual- versus a single-chamber implantable defibrillator in patients with slow ventricular tachycardias. Circulation 2004;110:1022-9.

29. Bokhari F, Newman D, Greene M, et al. Long-term comparison of the implantable cardioverter defibrillator versus amiodarone: eleven-year follow-up of a subset of patients in the Canadian Implantable Defibrillator Study (CIDS). Circulation 2004;110: 112-16.

30. Hohnloser SH, Kuck KH, Dorian P, et al. Prophylactic use of an implantable cardioverter-defibrillator after acute myocardial infarction. N Engl J Med 2004;351:2481-8.

31. Bänsch D, Kottkamp H, Grönefeld G, et al. The quick-implantabledefibrillator trial. Europace 2007;9:1144-50.

32. Reddy VY, Reynolds MR, Neuzil P, et al. Prophylactic catheter ablation for the prevention of defibrillator therapy. $N$ Engl J Med 2007;357:2657-65.

33. Russo AM, Day JD, Stolen K, et al. Implantable cardioverter defibrillators: do women fare worse than men? Gender comparison in the INTRINSIC RV trial. J Cardiovasc Electrophysiol 2009;20:973-8.

34. Kuck KH, Schaumann A, Eckardt L, et al. Catheter ablation of stable ventricular tachycardia before defibrillator implantation in patients with coronary heart disease (VTACH): a multicentre randomised controlled trial. Lancet 2010;375:31-40.

35. Varma N, Epstein AE, Irimpen A, et al. Efficacy and safety of automatic remote monitoring for implantable cardioverter-defibrillator follow-up: the Lumos-T Safely Reduces Routine Office Device Follow-up (TRUST) trial. Circulation 2010;122:325-32.

36. Cheng A, Nazarian S, Brinker JA, et al. Continuation of warfarin during pacemaker or implantable cardioverter-defibrillator implantation: a randomized clinical trial. Heart Rhythm 2011;8:536-40. 